1 WINTER BODY CONDITION IN THE COLLARED FLYCATCHER:

2 DETERMINANTS AND CARRY-OVER EFFECTS ON FUTURE BREEDING

3 PARAMETERS

4

5

6 Rita Hargitai, Gergely Hegyi, Márton Herényi, Miklós Laczi, Gergely Nagy, Balázs Rosivall,

7 Eszter Szöllősi, János Török

8

9

Behavioural Ecology Group, Department of Systematic Zoology and Ecology, Eötvös Loránd

11 University, Pázmány P. sétány 1/C, H-1117 Budapest, Hungary

12

13

14 Corresponding author:

15 Rita Hargitai

16 Behavioural Ecology Group, Department of Systematic Zoology and Ecology, Eötvös Loránd

17 University, Pázmány P. sétány 1/C, H-1117 Budapest, Hungary

18 E-mail: rita.hargitai@gmail.com

19

20

21

22

23

24 
1 ABSTRACT. - Factors determining the condition of migratory birds at their wintering sites are

2 poorly known. Age, sex, and morphological characteristics of birds may have an influence on

3 their winter condition by affecting their foraging and competitive abilities. Winter body

4 condition could have long-term consequences on the reproductive success of migratory birds

5 during the subsequent breeding season. Based on three years of data from Collared

6 Flycatchers (Ficedula albicollis), we examined the characteristics of winter-grown tail

7 feathers, as indicators of winter body condition, in relation to sex, age, morphological traits,

8 and future breeding variables. Tail feather mass was highly repeatable between years, but

9 feather growth rate was not repeatable, suggesting that the latter trait mainly indicates

10 environmental circumstances during molt, while feather mass may more strongly reflect

11 genetic effects. Tail feathers of male and adult birds showed better quality than those of

12 female and juvenile birds, possibly due to differences in individual quality and foraging skills quality, ptilochronology, winter molt.

between age classes and sexes, or winter habitat segregation between them. Birds with longer wings produced better-quality tail feathers, suggesting that wing and tail feather characteristics are similarly affected, presumably by individual genetic quality. Smaller Collared Flycatchers grew their tail feathers faster during the winter molt, possibly as they have better foraging ability due to better flight manoeverability. Tail feather quality showed no relationship with laying date, however, females that had produced heavier tail feathers during winter laid larger clutches during the following breeding season, suggesting that tail feather mass potentially reflects intrinsic individual quality.

Key words: body condition, clutch size, Ficedula albicollis, migratory passerine, plumage 
1 Factors determining the condition of migratory birds at their wintering sites are poorly known.

2 The age, sex and morphology of birds may all have an influence on their winter condition by 3 affecting their foraging and competitive abilities. Winter body condition could be an

4 important factor that determines arrival time, laying date and reproductive success of 5 migratory birds during the subsequent breeding season (Marra et al. 1998, Takaki et al. 2001, 6 Norris et al. 2004). For example, winter habitat quality influenced the condition and spring 7 departure dates of American Redstarts (Setophaga ruticilla), which in turn resulted in variable arrival times at the breeding areas (Marra et al. 1998). For migratory birds, early arrival is generally advantageous as it gives access to the best breeding sites and mates, higher food availability, as well as additional time to replace lost clutches (Perrins 1970, Nilsson and

\section{Svensson 1996).}

Plumage is replaced repeatedly over the lifetime of birds necessitated by the mechanical abrasion of feathers. As plumage is important in thermoregulation, protection, communication and locomotion, time spent molting should be minimized (Murphy et al. 1988). Avian molt is physiologically costly, not only in terms of energy, but also in the requirements for specific nutrients (Murphy and King 1992, Lindström et al. 1993), so molt parameters may vary with food quality and availability (Murphy et al. 1988, Swaddle and Witter 1997). Therefore, it is expected that individuals of the same species molting in habitats of different quality may show differences in plumage quality (Carlson 1998, Carbonell and Tellería 1999). Replacement of feathers may be slower and feathers may contain lower quantity of materials 21 when feather development competes for a limited supply of energy and specific nutrients 22 (Grubb 1989).

23 To estimate the body condition of birds during the period of molt, a technique called 24 ptilochronology has been successfully used (e.g. Murphy et al. 1988, Stratford and Stouffer 2001, Talloen et al. 2008). Growth bars across the vane of the feathers reflect the daily cycles 
1 of melanocyte activity with darker and lighter bands marking the growth during the day and

2 the night, respectively (Grubb 1989). Therefore, the width of the bars indicates daily feather

3 growth rate, and indirectly, the nutritional condition of an individual over the molt period

4 (Grubb 1989, Grubb and Cimprich 1990). It has been demonstrated that growth bar width of

5 feathers is influenced by food availability (Hill and Montgomerie 1994), territory size (Grubb

6 and Yosef 1992), habitat quality (Grubb and Yosef 1994), parasite infection (Saino et al.

7 2012, Marzal et al. 2013) and environmental stress (Talloen et al. 2008). Additionally,

8 individuals of high intrinsic quality may grow their feathers more rapidly than lower-quality

9 individuals, as suggested by the high within-individual repeatability of plumage

10 characteristics between molts (Takaki et al. 2001, De la Hera et al. 2009), and the significant

11 heritability of feather growth rate and mass (Gienapp and Merilä 2010, De la Hera et al. 12 2013).

13 Feathers may also be shorter and lighter under nutritional stress conditions as the 14 allocation of resources to plumage production may be limited (Murphy et al. 1988, Carbonell and Tellería 1999). Feather stiffness and hardness may be positively correlated with feather mass (Dawson et al. 2000), so feather mass could be an indirect measure of feather quality. One cost of having shorter and lighter feathers may be an impaired flight performance, which could affect foraging efficiency and increase predation risk (Slagsvold and Dale 1996). Also, lower-quality feathers might influence migration speed, prolonging the duration of migration (Marchetti et al. 1995, Hedenström and Alerstam 1998).

In this study, we examined the following associations in a migratory passerine, the Collared Flycatcher (Ficedula albicollis). First, we tested the repeatability of tail feather characteristics between consecutive years to see how much they may depend on stable individual quality versus changing environmental circumstances. Second, we investigated if stable traits (age, sex, tarsus length) and a characteristic that had been developed during the 
1 preceding summer molt (wing length) influenced winter condition, as reflected by tail feather

2 quality. The relationships between sex, age and feather growth rate have already been 3 analyzed in our previous study on a smaller dataset (Hargitai et al. 2012). Finally, we studied

4 the relationships between tail feather quality and the breeding variables (laying date, clutch 5 size) of birds during the following spring to examine whether conditions during winter could 6 have long-term life history consequences.

7

\section{MethodS}

Study species and field procedures.-The study was carried out in a nestbox-breeding population of Collared Flycatchers in an-oak dominated woodland in the Pilis Mountains ( $47^{\circ}$ $\left.43^{\prime} \mathrm{N}, 19^{\circ} 01^{\prime} \mathrm{E}\right)$, Hungary, in 2008-2010. The Collared Flycatcher is a long-distance migratory, hole-nesting, insectivorous passerine, which spends the winter in sub-Saharan Africa as confirmed by ringing recoveries and visual observations (Cramp and Perrins 1993). Flycatchers molt body feathers, tail feathers and tertials in their winter quarters (Svensson 2002). Birds were captured in the nestbox during the nestling feeding period. They were weighed with a Pesola spring balance (to the nearest $0.1 \mathrm{~g}$ ), the length of the tarsus was measured with a caliper (to the nearest $0.1 \mathrm{~mm}$ ), and the length of the wing was measured with a ruler (to the nearest $1 \mathrm{~mm}$ ). We determined the age (yearling or adult) of males from the color of remiges (Svensson 2002) or ringing data, while the age of females was determined from ringing data.

Feather measurements.-We plucked the left and right second outermost rectrices of birds during the nestling feeding period in each year (May-June), and stored them in envelopes 
1 until analyses. In 2010, we collected only one feather, as measurements strongly correlated

2 between left and right feathers (length: $r=0.85, n=235, P<0.001$, vane area: $r=0.63, n=$ $3228, P<0.001$, growth rate: $r=0.54, n=130, P<0.001$, feather mass: $r=0.81, n=334, P<$

4 0.001). We collected tail feathers from 172 (76 males and 96 females), 126 (68 males and 58

5 females) and 166 (95 males and 71 females) birds in 2008, 2009 and 2010, respectively. We

6 measured the width of eight growth bars perpendicular to the vane of the second rectrices as

7 described in Hargitai et al. (2012). We weighed the rectrices to the nearest $0.0001 \mathrm{~g}$ with a

8 Mettler AE200 digital balance. Also, we scanned the feathers, and measured the total length

9 of the feather from the calamus end to the feather tip, and the area of the vane with Scion Image program in 2008 and 2009. As we found that feather length and vane area are strongly correlated with feather mass (see below), we did not measure them in 2010. Where available, average values of the left and right feathers were used in the analyses.

Statistical analyses.-Data were analyzed with Pearson correlations and general linear models. In general linear models, a stepwise analysis based on backward deletion procedure was employed, removing non-significant $(P>0.05)$ interactions and main effects from the model one by one in decreasing order of $P$. We did not report the $F$ - and $P$-values of non-significant variables before elimination, as non-significance could be due to overparameterization of the model (Hegyi and Garamszegi 2011). Therefore, we re-integrated them to the final model one-by one, and present those $F$ - and $P$-values. We analyzed the relationships between various tail feather traits with Pearson correlations. The repeatabilities of feather traits between consecutive years were analyzed only for adult birds with Pearson correlations. We tested the effects of stable (age, sex, tarsus length) or summer-developed (wing length) traits on tail feather quality by including age (yearling or adult), sex, and year as factors, and tarsus 
1 feather mass as the dependent variables. We calculated standardized effect sizes for predictor

2 variables (McNeil et al. 1996). Second-order interactions between factors and continuous

3 variables were included in the models, but only significant interactions are reported.

$4 \quad$ We examined the relationships between tail feather traits and future breeding variables by 5 using laying date and clutch size (5-8 eggs) as dependent variables, age, sex, year as fixed

6 factors, and growth rate and feather mass as continuous predictor variables. Laying date was 7 entered as the deviation from the median laying date in the particular year. In the model with clutch size as dependent variable, laying date was a covariate.

Wing length was significantly affected by age $(P<0.001)$ and sex $(P<0.001)$, laying date was affected by age $(P=0.05)$, while body mass differed among years $(P=0.026)$ and sexes $11(P<0.001)$, so they were standardized for these factors (mean $=0$, SD $=1)$, and the standardized variables were used as independent variables in the tests. Moreover, we used year-, sex- and age-standardized feather growth rate and feather mass when they were included as independent variables in the models. In the analyses of variables of the breeding season (laying date and clutch size), we used only those nests where no experimental manipulation had been performed. Analyses were performed in STATISTICA, version 5.5 (StatSoft Inc., Tulsa, OK, USA), and figures were prepared in SPSS 19. (IBM-SPSS Inc., Chicago, IL, USA).

Correlation between winter-grown tail feather traits.-We found positive correlations between 
1 growth rate and mass in further analyses, as feather length and vane area correlated strongly

2 positively with feather mass (Table 1).

4 Repeatability of feather quality. -We analyzed the repeatability of feather traits of adult

5 Collared Flycatchers between consecutive years. According to our results, tail feather mass

6 correlated strongly between years $(r=0.79, n=32, P<0.001$, Fig 1). However, feather 7 growth rate showed no repeatability between years $(r=0.33, n=15, P=0.23)$. Regarding wing feathers, we also found a high repeatability of wing length between years $(r=0.79, n=$ $69, P<0.001)$.

Stable and summer-developed traits and winter-grown tail feather quality.-The tail feathers of male and adult Collared Flycatchers were heavier and grew faster than those of female and juvenile birds, respectively (Table 2). We also investigated whether growth rate and mass of tail feathers varied significantly within the adult age category, but we found no significant variation in these variables between 2 and 5 years of age (growth rate: $F_{3,118}=0.95, P=0.42$; mass: $\left.F_{3,163}=0.61, P=0.61\right)$. There was also a difference in wing length between the sexes and age classes: males and adult birds had longer wings (sex: $F_{1,375}=119.09, P<0.001$; age: $\left.F_{1,375}=83.88, P<0.001\right)$. However, there was no difference in tarsus length between the sexes and age classes (sex: $F_{1,377}=0.04, P=0.83$; age: $F_{1,377}=1.01, P=0.32$ ). Our results showed that birds with longer wings and with smaller body size produced tail feathers which grew faster (Table 2). We also found a positive correlation between wing length and the mass of winter-grown tail feathers (Table 2, Fig. 2).

Winter-grown tail feather quality and future breeding variables.-We found that Collared 
1 during the subsequent breeding season $\left(F_{1,48}=3.95, P=0.05\right.$, st. effect size $=0.28$, Fig. 3$)$.

2 When we included spring female body mass and tarsus length as covariates in the model, the

3 effect of tail feather mass on future clutch size remained significant $\left(F_{1,43}=5.20, P=0.03\right.$, st.

4 effect size $=0.33$; mass: $F_{1,43}=0.23, P=0.63$; tarsus: $\left.F_{1,43}=1.97, P=0.17\right)$. However,

5 feather growth rate showed no association with the clutch size of females $\left(F_{1,47}=0.96, P=\right.$ 6 0.33). According to our results, laying date was not related to either tail feather trait (feather 7 growth rate: $F_{1,168}=0.10, P=0.75$; feather mass: $F_{1,168}=0.34, P=0.56$ ).

\section{DISCUSSION}

We found positive correlations between tail feather growth rate, length, vane area and mass, suggesting that these traits are similarly affected by the quality of the individual or the molting environment. Likewise, in the Blackcap (Sylvia atricapilla) and the Gray Jay (Perisoreus canadensis), it has been demonstrated that individuals with a faster feather growth rate produced longer feathers (Waite 1990, De La Hera et al. 2009). In contrast, no significant correlation was found between feather growth rate and tail length in the Styan's Grasshopper Warbler (Locustella pleskei; Takaki et al. 2001) and the Siberian Jay (Perisoreus infaustus; Gienapp and Merilä 2010).

Adult Collared Flycatchers produced similar feathers in two consecutive winter molts, as shown by the highly repeatable mass of their rectrices. However, feather growth rate showed no repeatability between years. In accordance with our results, De La Hera et al. (2009) also found high repeatability in the length and mass of Blackcap tail feathers, and no significant repeatability in feather growth rate between molts. In contrast, in a study of Styan's Grasshopper Warbler, feather growth rate showed a significant positive correlation between 
1 years (Takaki et al. 2001). In the Pied Flycatcher (Ficedula hypoleuca), feather mass also

2 showed high repeatability and heritability, suggesting that genetic variation accounts for a

3 considerable proportion of phenotypic variation of this feather trait (de la Hera et al. 2013).

4 This result implies that the mass of tail feathers depends rather on individual genetic factors

5 or early environmental effects than on the environmental quality of the molting habitat. In

6 contrast, feather growth rate seems to be more affected by environmental factors at the time of

7 feather production.

Our results showed that Collared Flycatcher males possessed heavier tail feathers than did females. In a study of Northern Cardinals (Cardinalis cardinalis), it has also been found that males grew longer rectrices than did females (Grubb et al. 1991). Collared Flycatchers are 11 sexually dimorphic in their coloration (Svensson 2002). Although wing and tail feathers of males were longer than those of females, tarsus length, which is related to skeletal body size, did not differ between the sexes. There could be a selective pressure for males to have longer, larger and heavier feathers. Better feathers could help males to increase flight performance in terms of speed (Savile 1957, Balmford et al. 1993, Marchetti et al. 1995), which could be important for earlier spring arrival at the breeding grounds and thus the occupation of betterquality nesting areas. Indeed, male Collared Flycatchers generally arrive earlier to the breeding sites than females (Mitrus 2004, our pers. obs.). Furthermore, better flight ability could also be important in male-male competitions for breeding sites and in escape from predator attacks due to their conspicuous plumage and courtship behavior.

We found that male Collared Flycatchers had faster tail feather growth rate than females (see also Hargitai et al. 2012). It is possible that sex-related physiological, metabolic or endocrine differences caused the faster feather growth rate of male birds, and not their relatively better body condition. Alternatively, males may occupy better-quality territories due to their dominance over females (Piper 1997, Marra 2000, Catry et al. 2004), and thus males 
1 develop their feathers faster (Gienapp and Merilä 2010, but see Saino et al. 2012). In support

2 of this hypothesis, a study of Downy Woodpeckers (Picoides pubescens) showed that females

3 grew their feathers slower in woods without food-supplementation, however, in food-

4 supplemented sites, feather growth rate did not differ between the sexes (Grubb 1989). These

5 results suggest that the faster feather growth rate of males may indicate their better nutritional

6 status, probably due to their social dominance. Indeed, in a study of Swedish Collared

7 Flycatchers, it has been suggested that males winter in less arid habitats than females

8 (Hjernquist et al. 2009).

We found that the tail feathers of juvenile birds were lighter and grew slower than those of adult birds (see also Hargitai et al. 2012), however, there was no difference in feather quality among 2-5 year-old birds. Wing length also differred between juvenile and adult Collared Flycatchers: juveniles had shorter wings. Juvenile birds may winter in less suitable areas with poorer availability and quality of food, thus, the quality of their tail feathers may be lower. Supporting this hypothesis, it has been observed in some passerines that older males forced most juveniles into habitats of poorer quality during winter (Marra and Holberton 1998, Catry et al. 2004). Alternatively, juveniles may be less experienced foragers or otherwise lowerquality individuals (Cam and Monnat 2000, Hegyi et al. 2006), which may not allow them to develop high-quality feathers (Grubb et al. 1991, Gienapp and Merilä 2010).

We also analyzed if summer-developed and stable morphological traits (wing and tarsus lengths) of birds had an effect on their winter condition, as indicated by winter-grown tail feather quality. We found that birds with longer wings produced tail feathers which grew faster and were heavier. The mechanism underlying such link could be either the effect of environmental or genetic factors. A longer wing may allow the bird to fly faster and cover a longer distance (Marchetti et al. 1995) seeking an optimal winter habitat with better food availability. Moreover, a bird with longer wings may have better foraging ability due to 
1 higher speed (Savile 1957), and therefore it may molt faster and grow heavier tail feathers. It

2 is also possible that both wing and tail feather quality reflect the same genetically determined

3 individual quality rather than that of the molting environment. This latter hypothesis is also

4 supported by the strong within-individual repeatability of tail feather mass and wing length

5 between consecutive years. Alternatively, length of wing and mass of tail feathers may be

6 genetically positively linked and may have evolved under natural selection in order to achieve

7 an aerodynamically optimal body shape for flight (Thomas 1993, Møller et al. 1995).

8 Nevertheless, this hypothesis does not exclude the possibility that individuals capable of

9 producing both longer wing and heavier tail feathers have generally better quality, as it

10 requires more resources (Murphy and King 1992, Lindström et al. 1993). This supposition is

11 also supported by the observation that adult birds, which probably have higher intrinsic

12 quality than juveniles (Cam and Monnat 2000, Hegyi et al. 2006), had both longer wing and 13 heavier tail feathers than juveniles.

14 We also found that smaller Collared Flycatchers grew their tail feathers faster during the winter molt. A smaller bird may perform better in foraging due to its better flight manoeverability (Andersson and Norberg 2008), which is especially important in species like flycatchers, which capture flying insects (Löhrl 1976, Török 1986).

Birds spending the winter in a poor habitat could lose some of their body mass (Marra et al. 1998), which could have long-term consequences, leading to delayed departure dates in the spring, and later arrival at the breeding area (Marra et al. 1998, Norris et al. 2004, Saino et al. 2004). In addition, birds producing better quality feathers during the winter molt may have better flight performance, and thus these birds may arrive earlier at the breeding site and consequently show higher reproductive success. In concert with this hypothesis, Takaki et al. (2001) and Marzal et al. (2013) found that birds that had higher tail feather growth rates, reflecting better nutritional condition during the winter molt, arrived earlier and acquired a 
1 mate faster in the subsequent breeding season. However, in contrast to our expectations, we

2 detected no relationships between tail feather characteristics of Collared Flycatchers and their

3 laying date of the breeding season following feather molt, although, we must note that we did

4 not record the arrival time of birds. Similarly, no relationships have been observed between

5 feather mass and spring arrival time and laying date in the Pied Flycatcher (de la Hera et al.

6 2013), suggesting that in flycatchers winter condition does not predict the laying date of 7 individuals.

We found that the tail feather growth rate of Collared Flycatchers showed no relationship with future breeding performance. Similarly, in Barn Swallows (Hirundo rustica) and Siberian Jays, feather growth rate showed no association with the reproductive performance 11 of females (Gienapp and Merilä 2010, Saino et al. 2012). In Styan's Grasshopper Warblers, females with wider tail feather growth bars tended to achieve higher reproductive success, probably as a result of breeding earlier (Takaki et al. 2001). Likewise, in House Martins (Delichon urbica), birds with a higher tail feather growth rate started breeding earlier and consequently laid larger clutches and produced more fledglings, but no significant relationship between tail feather growth rate and the number of fledglings produced was detected (Marzal et al. 2013). These results are in agreement with our findings suggesting that winter-developed feather growth rate does not show a direct relationship with future reproductive performance, although in some species it may have an indirect effect on reproductive success by influencing the laying date of birds.

Most of the studies tested the relationship between feather growth rate and reproductive success, while studies on tail feather mass or length are lacking. Our results indicated that Collared Flycatcher females that had grown heavier tail feathers during winter laid larger clutches during the subsequent breeding season, although we must note that the association was just significant. A possible explanation for such link could be that heavier feathers may 
1 help females to forage more efficiently during the egg-laying period and thus produce larger

2 clutches. Alternatively, these birds may be generally higher-quality individuals, which can

3 both develop high-quality feathers during winter molt and lay larger clutches during spring.

4 Accordingly, tail feather mass could be a reliable indicator of the quality of female Collared

5 Flycatchers.

6 In summary, our results suggest that tail feather mass of Collared Flycatchers is highly 7 repeatable, correlates with wing length, and shows a relationship with future clutch size in 8 females, thus potentially reflecting intrinsic individual quality. In contrast, feather growth rate 9 could rather indicate the environmental circumstances during molting. The winter condition 10 of birds seemed to be affected by several variables, including age, sex, year, wing length and 11 body size. However, we failed to find any indication that body condition at their wintering 12 sites in Africa has significant consequences on the laying date of Collared Flycatchers. 13 Further research based on the analysis of trace elements or stable isotopes in feathers 14 (Procházka et al. 2008, Hjernquist et al. 2009, Szép et al. 2009) could be applied to outline 15 groups of individuals that molted in the same areas during winter.

16

\section{ACKNOWLEDGEMENTS}

We are grateful to Gy. Blázi, R. Főző, L. Z. Garamszegi, D. Kiss, G. Markó and several students for assistance during fieldwork. We thank two anonymous reviewers for their helpful comments. This study was supported by the Hungarian Scientific Research Fund (OTKA, grants no. 68295, 75618, 100304, and 101611), the Eötvös Loránd University, the Erdők a Közjóért Alapítvány, the Pilis Park Forestry, and the Bolyai János Research Fellowship to 
1 R.H. The Hungarian Ministry of Environment and Water provided permissions for this study

2 (KTVF 30871-1/2008 and KTVF 43355-1/2008).

3

4

\section{LITERATURE CITED}

Andersson, M., and R. Å. Norberg. 2008. Evolution of reversed sexual size dimorphism and role partitioning among predatory birds, with a size scaling of flight performance. Biological Journal of the Linnean Society 15:105-130.

Balmford, A., A. L. R. Thomas, and I. L. Jones. 1993. Aerodynamics and the evolution of long tails in birds. Nature 361:628-631.

Cam, E., and J-Y. Monnat. 2000. Apparent inferiority of first-time breeders in the kittiwake: the role of heterogeneity among age-classes. Journal of Animal Ecology 69:380-394.

Carbonell, R., and J. L. Tellería. 1999. Feather traits and ptilochronology as indicators of stress in Iberian Blackcaps Sylvia atricapilla. Bird Study 46:243-248.

Carlson, A. 1998. Territory quality and feather growth in the white-backed woodpecker Dendrocopos leucotos. Journal of Avian Biology 29:205-207.

Catry, P., A. Campus, V. Almada, and W. Cresswell. 2004. Winter segregation of migrant European robins Erithacus rubecula in relation to sex, age and size. Journal of Avian Biology 35:204-209.

Cramp, S., and C. M. Perrins. 1993. The Birds of the Western Palearctic. Oxford University Press, Oxford, United Kingdom.

Dawson, A., S. A. Hinsley, P. N. Ferns, R. H. C. Bonser, and L. Eccleston. 2000. Rate of moult affects feather quality: a mechanism linking current reproductive effort to future survival. Proceedings of the Royal Society London B 267:2093-2098. 
1 De la Hera, I., J. Pérez-Tris, and J. L. Tellería. 2009. Repeatable length and mass but not 2 growth rate of individual feathers between moults in a passerine bird. Acta Ornithologica 44:95-99.

De la Hera, I., T. E. Reed, F. Pulido, and M. E. Visser. 2013. Feather mass and winter moult (1) extent are heritable but not associated with fitness-related traits in a long-distance migratory bird. Evolutionary Ecology 10.1007/s10682-013-9639-x

Gienapp, P. and J. Merilä. 2010. Genetic and environmental effects on a condition-dependent trait: feather growth in Siberian jays. Journal of Evolutionary Biology 23:715-723.

Grubb, T. C. Jr. 1989. Ptilochronology: feather growth bars as indicators of nutritional status. Auk 106:314-320.

Grubb, T. C. Jr., and

D. A. Cimprich. 1990. Supplementary food improves the nutritional condition of wintering woodland birds: evidence from ptilochronology. Ornis Scandinavica 21:277-281.

Grubb, T. C. Jr., T. Waite, and A. J. Wiseman. 1991. Ptilochronology: induced feather growth in northern cardinals varies with age, sex, ambient temperature, and day length.Wilson Bulletin 103:435-445.

Grubb, T. C. Jr., and R. Yosef. 1992.Territory size influences nutritional condition in nonbreeding loggerhead shrikes (Lanius ludovicianus) - a ptilochronology approach. Conservation Biology 6:447-449.

Hargitai, R, G. Hegyi, and J. Török. 2012. Winter body condition in relation to age, sex and

Grubb, T. C. Jr, and R. Yosef. 1994. Habitat-specific nutritional condition in the loggerhead shrikes (Lanius ludovicianus): evidence from ptilochronology. Auk 111:756-759.

24 Hedenström, A., and T. Alerstam. 1998. How fast can birds migrate. Journal of Avian Biology 29:424-432. 
1 Hegyi, G., and L. Z. Garamszegi. 2011. Using information theory as a substitute for stepwise 2 regression in ecology and behavior. Behavioural Ecology and Sociobiology 65:69-76.

3 Hegyi, G., J. Török, L. Tóth, L. Z. Garamszegi, and B. Rosivall. 2006. Rapid temporal change in the expression and age-related information content of a sexually selected trait. Journal of Evolutionary Biology 19:228-238.

Hill, G. E., and R. Montgomerie. 1994. Plumage colour signals nutritional condition in the house finch. Proceedings of the Royal Society B 258:47-52.

Hjernquist, M. B., T. Veen, L. Font, and M. Klaasen. 2009. High individual repeatability and population differentiation in stable isotope ratios in winter-grown Collared Flycatcher Ficedula albicollis feathers. Journal of Avian Biology 40:102-107.

Lindström, A, G. H. Visser, and S. Daan. 1993. The energetic cost of feather synthesis is proportional to basal metabolic rate. Physiological Zoology 66:490-510.

Löhrl, H. 1976. Studies of less familiar birds. Collared Flycatcher. British Birds 69:20-26.

Marchetti, K., T. Price, and A. Richman. 1995. Correlates of wing morphology with foraging behaviour and migration distance in the genus Phylloscopus. Journal of Avian Biology 26:177-181.

Marra, P. P. 2000 The role of behavioral dominance in structuring patterns of habitat occupancy in a migrant bird during the nonbreeding season. Behaviral Ecology 11:299-

Marra, P. P., K. A. Hobson, and R. T. Holmes. 1998. Linking winter and summer events in a migratory bird by using stable-carbon isotopes. Science 282:1884-1886.

Marra, P. P., and R. L. Holberton. 1998. Corticosterone levels as indicators of habitat quality: effects of habitat segregation in a migratory bird during the non-breeding season. Oecologia 116:284-292. 
1 Marzal, A., M. Reviriego, I. G. Hermosell, J. Balbontín, S. Bensch, C. Relingque, L.

2 Rodríguez, L. Garcia-Longoria, and F. de Lope. 2013. Malaria infection and feather 3 growth rate predict reproductive success in house martins. Oecologia 171:853-861.

4 McNeil, K., I. Newman, and F. J. Kelly. 1996. Testing Research Hypotheses with the General

Mitrus, C. 2004. No effect of age of males on reproductive success of the Collared Flycatcher Ficedula albicollis. Folia Zoologica 53:319-328.

Møller, A. P., F. de Lope, and N. Saino. 1995. Sexual selection in the barn swallow Hirundo rustica. VI. Aerodynamic adaptations. Journal of Evolutionary Biology 8:671-687.

Murphy, M. E., and J. R. King. 1992. Energy and nutrient use during moult by white-crowned sparrows Zonotrichia leucophrys gambelii. Ornis Scandinavica 23:304-313.

Murphy, M. E., J. R. King, and J. Lu. 1988. Malnutrition during the postnuptial molt of whitecrowned sparrows: feather growth and quality. Canadian Journal of Zoology 66:14031413.

Nilsson, J.-Å., and E. Svensson. 1996. The cost of reproduction: a new link between current reproductive effort and future reproductive success. Proceedings of the Royal Society B

Norris, D. R., P. P. Marra, T. K. Kyser, T. W. Sherry, and L. M. Ratcliffe. 2004. Tropical winter habitat limits reproductive success on the temperate breeding grounds in a migratory bird. Proceedings of the Royal Society B 271:59-64.

Perrins, C. M. 1970. The timing of birds' breeding seasons. Ibis 112:242-255.

Piper, W. H. 1997. Social Dominance in Birds: Early Findings and New Horizons. Springer, New York, USA. 
1 Procházka, P., K. A. Hobson, Z. Karcza, and J. Kralj. 2008. Birds of a feather winter together: migratory connectivity in the Reed Warbler Acrocephalus scirpaceus. Journal of Ornithology 149:141-150.

Saino, N., M. Romano, M. Caprioli, R. Ambrosini, D. Rubolini, C. Scandolara, and A. Romano. 2012. A ptilochronological study of carry-over effects of conditions during wintering on breeding performance in the barn swallow Hirundo rustica. Journal of Avian Biology 43:513-524.

Saino, N., T. Szép, M. Romano, D. Rubolini, F. Spina, and A. P. Møller. 2004. Ecological conditions during winter predict arrival date at the breeding quarters in a trans-saharan migratory bird. Ecology Letters 7:21-25.

Savile, D. B. O. 1957. Adaptive evolution in the avian wing. Evolution 11:212-224.

Slagsvold, T., and S. Dale. 1996. Disappearance of female pied flycatchers in relation to breeding stage and experimentally induced molt. Ecology 77:461-471.

Stratford, J. A., and P. C. Stouffer. 2001. Reduced feather growth rates of two common birds inhabiting Central Amazonian forest fragments. Conservation Biology 15:721-728.

Svensson, L. 2002. Identification Guide to European Passerines. Svensson, Stockholm, Sweden.

Swaddle, J. P., and M. S. Witter. 1997. Food availability and primary feather molt in European starlings, Sturnus vulgaris. Canadian Journal of Zoology 75:948-953.

Szép, T., K. A. Hobson, J. Vallner, S. E. Piper, B. Kovács, D. Z. Szabó, and A. P. Møller. 2009. Comparison of trace element and stable isotope approaches to the study of migratory connectivity: an example using two hirundine species breeding in Europe and wintering in Africa. Journal für Ornithology 150:621-636.

Takaki, Y., K. Eguchi, and H. Nagata. 2001. The growth bars on tail feathers in the male Styan's Grasshopper Warbler may indicate quality. Journal of Avian Biology 32:319-325. 
1 Talloen, W., L. Lens, S. Van Dongen, and E. Matthysen. 2008. Feather development under

2 environmental stress: lead exposure effects on growth patterns in great tits Parus major. $3 \quad$ Bird Study 55:108-117.

4 Thomas, A. L. R. 1993. On the aerodynamics of birds' tails. Philosophical Transactions of the $5 \quad$ Royal Society London B 340:361-380.

6 Török, J. 1986. Food segregation in three hole-nesting bird species during the breeding $7 \quad$ season. Ardea 74:129-136.

8 Waite, T. A. 1990. Effects of caching supplemental food on induced feather regeneration in 9 wintering gray jays Perisoreus canadensis: a ptilochronology study. Ornis Scandinavica 21:122-128. 
1 TABLE 1. Correlation matrix of various tail feather traits of Collared Flycatchers.

2

\begin{tabular}{lcccc} 
& & Length & Vane area & Mass \\
\hline Growth rate & $r$ & $0.32 * * *$ & $0.25 * * *$ & $0.17 * *$ \\
& $n$ & 158 & 158 & 275 \\
Length & $r$ & & $0.47 * * *$ & $0.31 * * *$ \\
& $n$ & 202 & 202 \\
Vane area & $r$ & & & $0.33^{* * *}$ \\
& $n$ & & 202 \\
\hline
\end{tabular}

3

$4 \quad * *: \mathrm{P}<0.01 ; * * *: \mathrm{P}<0.001$

5

6

7

8

9

10

11

12

13

14

15

16 
1 TABLE 2. Tail feather quality of Collared Flycatchers in relation to sex, age, year and 2 morphological traits. Wing length was standardized for age and sex (mean $=0, \mathrm{SD}=1)$.

\begin{tabular}{|c|c|c|c|c|c|c|c|c|}
\hline & \multicolumn{4}{|c|}{ Growth rate } & \multicolumn{4}{|c|}{ Feather mass } \\
\hline & $\mathrm{df}$ & $F$ & $P$ & st. effect size & $\mathrm{df}$ & $F$ & $P$ & st. effect size \\
\hline Age & 1,265 & 17.27 & $<0.001$ & 0.25 & 1,370 & 7.21 & 0.008 & 0.14 \\
\hline Sex & 1,265 & 12.55 & $<0.001$ & 0.21 & 1,370 & 275.27 & $<0.001$ & 0.65 \\
\hline Year & 2,265 & 10.35 & $<0.001$ & 0.27 & 1,370 & 118.42 & $<0.001$ & 0.62 \\
\hline Wing length & 1,265 & 6.60 & 0.011 & 0.16 & 1,370 & 31.42 & $<0.001$ & 0.28 \\
\hline Tarsus length & 1,265 & 5.00 & 0.026 & -0.14 & 1,369 & 0.02 & 0.87 & 0.01 \\
\hline
\end{tabular}

4

5

6

7

8

9

10

11

12

13

14

15 
FIG. 1. Repeatability of tail feather mass of adult Collared Flycatchers between 2 consecutive years. The dashed line indicates a reference 1:1 line.

3

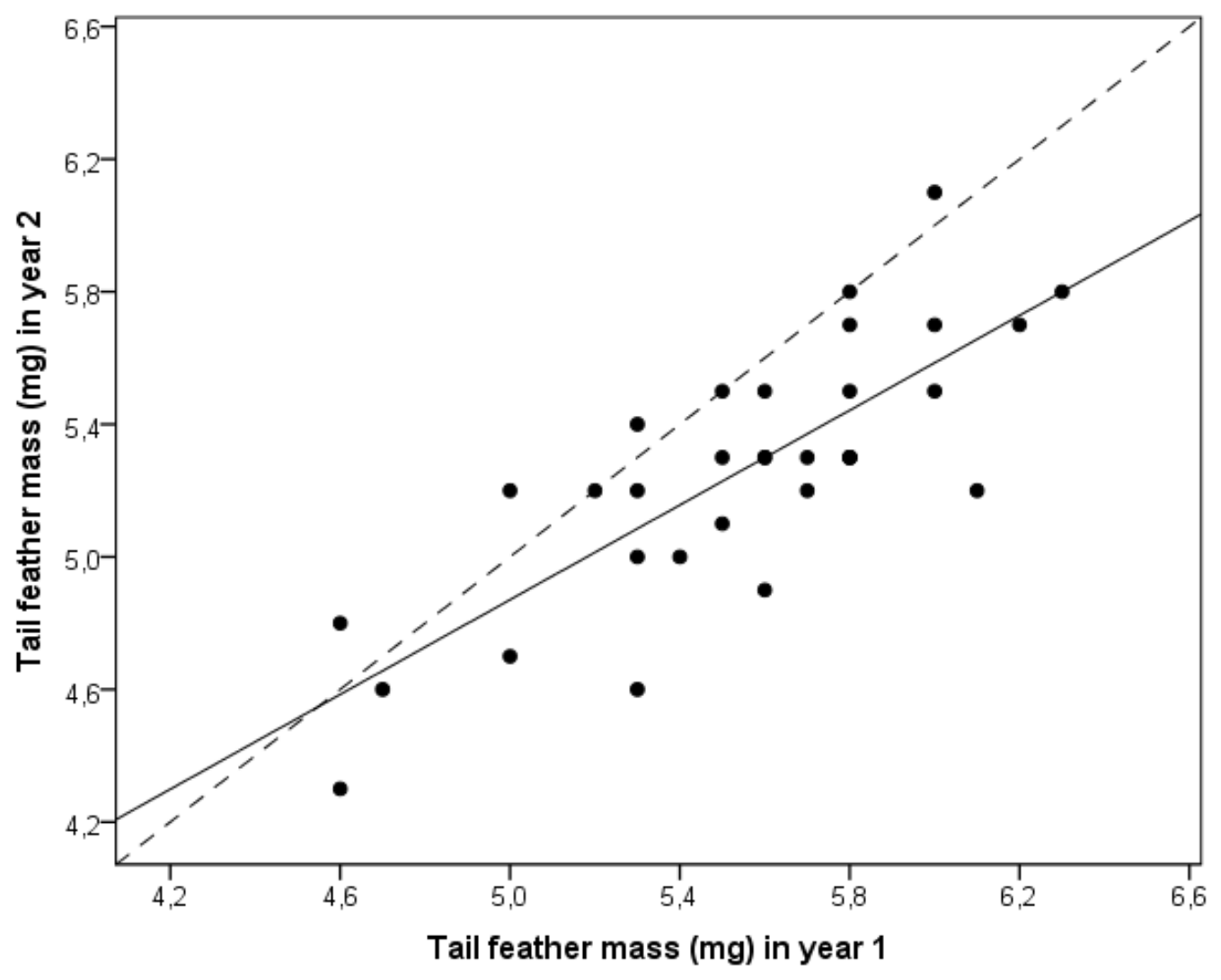

4

5

6

7

8

9

10

11

12

13

14 
FIG. 2. Relationship between wing length and tail feather mass of Collared Flycatchers.

2 Wing length was standardized for age and sex, and tail feather mass was standardized for sex,

3 age and year $($ mean $=0, \mathrm{SD}=1)$.

4

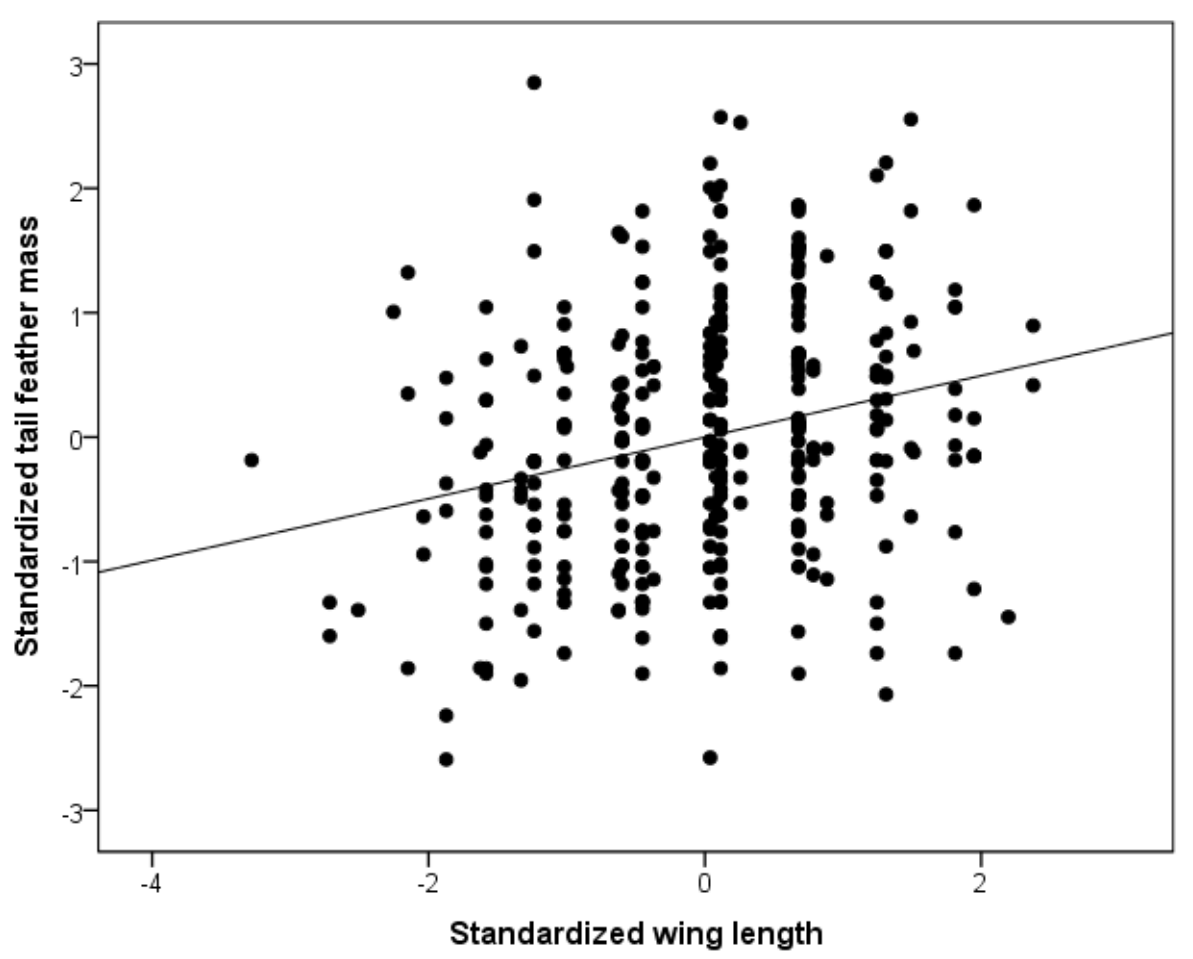

5 
FIG. 3. Relationship between tail feather mass and clutch size of female Collared

2 Flycatchers. Tail feather mass and clutch size were standardized for year and age (mean $=0$, $3 \mathrm{SD}=1)$.

4

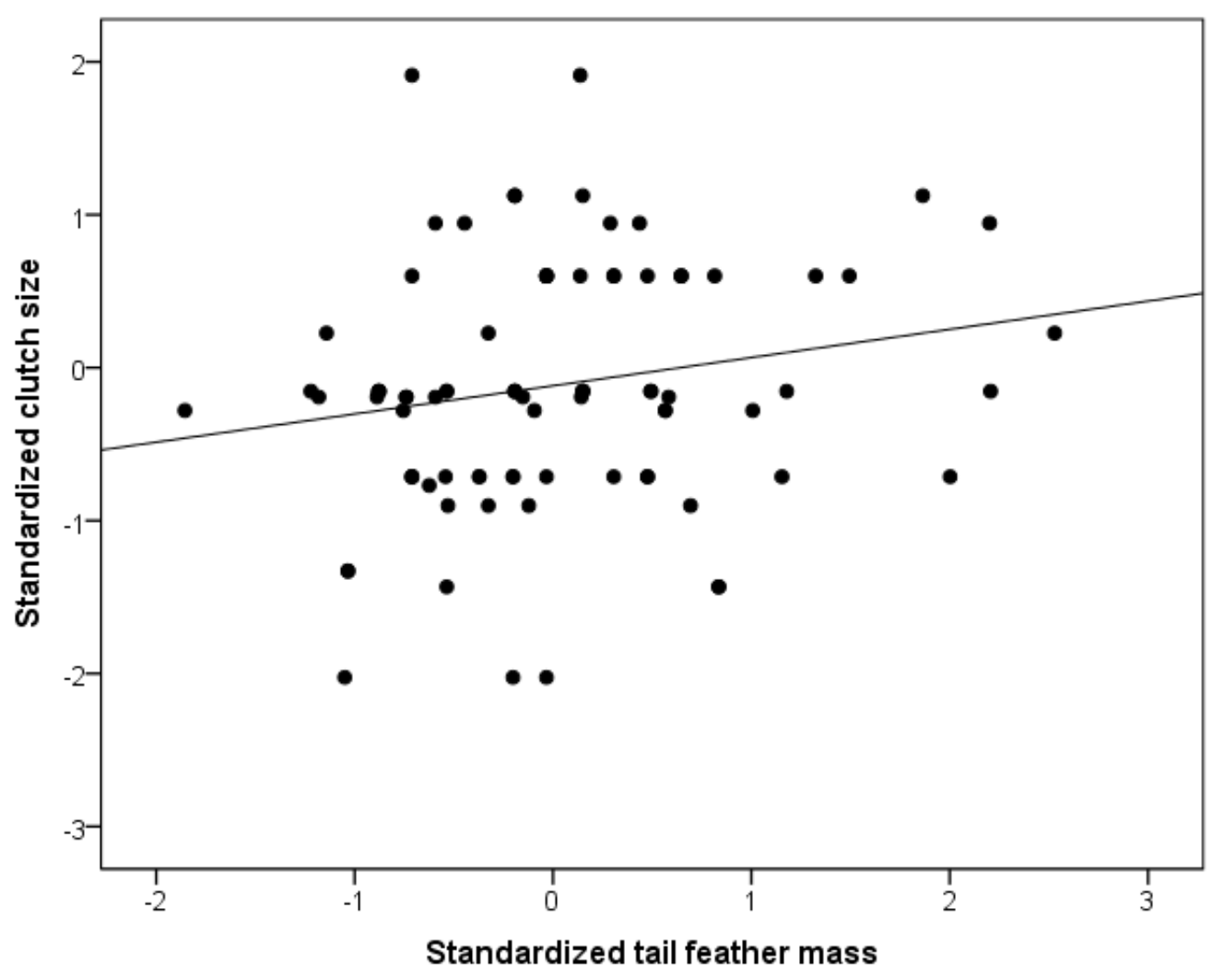

5

6

7

8

9

10

11

12

13

14 